\title{
EMBO Workshop
}

\section{Molecular Biology of}

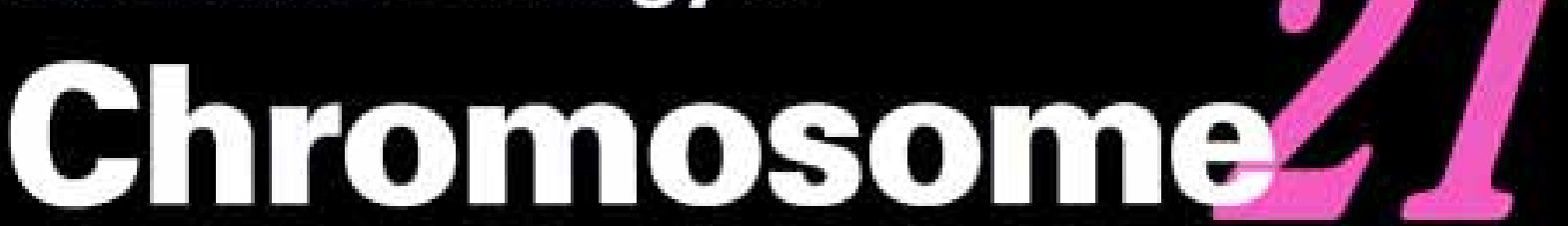

\& Down Syndrome

Abstracts of the 8th International Meeting

\section{Israel \\ 6-10 June 1999}

Organizers:

Y. Groner

S. Antonarakis

D. Levanon 


\title{
Summary Report ${ }^{1}$
}

\author{
Y. Gronera, S.E. Antonarakis ${ }^{b}$, D. Levanon ${ }^{a}$ \\ ${ }^{a}$ Weizmann Institute of Science, Israel, and ${ }^{b}$ University of Geneva Medical School, Switzerland
}

The 8th International meeting on Human Chromosome 21 was held in two different places in Israel. The Weizmann Institute of Science in Rehovot on June 7, 1999 and the Beit Gabriel Complex in Ma'agan, Sea of Galilee on June 8-10, 1999. The meeting attracted 82 scientists from all over the world to discuss the progress on biological research related to genes on human chromosome 21, and plan for future research orientations and collaborations. The history of this meeting is of interest. About a decade ago, when the Human Genome project was about to officially start, the scientific communities and the funding agencies felt the need for single chromosome workshops to discuss and monitor the progress, and to create comprehensive maps of the various human chromosomes. The scientific community interested in the genomic affairs of chromosome 21 always served as a model for these meetings. The previous chromosome 21 single chromosome workshops, as they used to be called, were held in Bethesda, Maryland 1990 (organized by D. Cox), Denver, Colorado 1991 (organized by D. Patterson), Baltimore, Maryland 1992 (organized by S.E. Antonarakis), Paris, France 1993 (organized by J. Delabar), Tsukuba, Japan 1994 (organized by N. Shimizu), Cold Spring Harbor, New York 1996 (organized by J. Korenberg) and Berlin, Germany 1997 (organized by M.L. Yaspo and K. Gardiner). The contents of the meetings were also representative of the different phases and preoccupations of the genome research in this decade. The early '90s meetings were populated with presentations on the linkage maps and tools for creating physical maps; the mid '90s meetings with comparisons of physical maps and arrangement of contigs; the late ' 90 s with sequencing and transcription maps.

The Israel meeting was revolutionary in its title; for the first time, the word biology appeared and replaced the word map-

Y. Groner, Department of Molecular Genetics, Weizmann Institute of Science, Rehovot, 76100 (Israel)

1 A summary report on this EMBO workshop will also be published in a forthcoming issue of the EMBO Journal. The abstracts and summary report appearing in Cytogenetics and Cell Genetics Vol. 86, No. 1, 1999 are published with the permission of EMBO.

KARGER E-mail karger@karger.ch

(c) 1997 S. Karger AG, Basel

Fax + 41613061234

http://www.karger.com ping. Was this because mapping and sequencing of chromosome 21 are already finished? Certainly not. But this title shifts the emphasis now on the function of chromosome 21 encoded proteins, their environment in normal development and their involvement in numerous monogenic disorders, susceptibility traits, and above all, the various phenotypes of Down syndrome.

The discussions and presentations during this meeting can be summarized as follows. The progress on the transcription map of $\mathrm{HC} 21$ was impressive since several laboratories are cloning and characterizing genes. A total of 112 transcription units have been determined to date (full length cDNAs experimentally verified). The nucleotide sequencing of the chromosome is also well advanced. A total of approximately 18 megabases have been sequenced (high quality, no gaps, with editing and proofreading). The sequencing groups agreed to continue the high quality sequencing effort for the entire $21 \mathrm{q}$ up to marker H2-112 (a total of 33 megabases) in the next 6-12 months. After that, a region of 4-6 megabases in the centromeric part of $21 \mathrm{q}$ will remain to be sequenced. The elucidation of the molecular basis of the various phenotypes of Down syndrome took a major part of the presentations, posters and discussions. The use of animal models including the mouse was repeatedly emphasized. The phenotypic evaluation of mice with partial trisomy 21 , and those with overexpression or targeted disruption of single genes were also extensively discussed. In addition, the studies on the molecular pathophysiology of single gene disorders were presented. In depth description of functional studies for selected genes were also included in the program. Lively discussions on the use of methods for assessment of global gene expression differences in trisomy 21 cells and tissues, attracted the interest of participants since these methods are likely to be used in many future studies. The potential for initial attempts to reduce the levels of selected chromosome 21 encoded proteins by oligonucleotides as one approach to eventual therapeutic interventions were also presented and debated.

The participants left the meeting with excellent memories of the scenic views over the Sea of Galilee, the late night discussions by the beach, the "Kumzitz" of the last night and the warm hospitality of the local organizers and the Israeli people. 